\title{
The Conceptual Mapping and Its Importance in Nursing Education and Practice
}

\author{
Usha Rani Kandula, Addisu Dabi Wake* \\ Nursing Department, College of Health Sciences, Arsi University, Asella, Ethiopia \\ Email address: \\ neha2010dec@gmail.com (U. R. Kandula), addansa12@gmail.com (A. D. Wake) \\ ${ }^{*}$ Corresponding author
}

\section{To cite this article:}

Usha Rani Kandula, Addisu Dabi Wake. The Conceptual Mapping and Its Importance in Nursing Education and Practice. International Journal of Clinical and Experimental Medical Sciences. Vol. 7, No. 4, 2021, pp. 86-90. doi: 10.11648/j.ijcems.20210704.13

Received: May 13, 2021; Accepted: July 2, 2021; Published: July 9, 2021

\begin{abstract}
Conceptual maps are observed as new and efficient teaching and learning tools for the student learning process. These maps are educational useful tools for teachers and learners; it creates significant knowledge on a specific subject and represents it in a schematic manner. Concept maps are one of the significant teaching methods that support learners precisely attain the information they want. It is a learning and teaching strategy which links how the individuals learn and meaningful learning issues. In nursing, the concept maps are used as a scheme of uniting theory and practice. It enhances the selfconfidence, achievement, and the ability of developing a critical thinking skill. A conceptual diagram utilizes a graphic conceptual framework to visually organize information or learning content with the assist of predefined groups. These groups are generally resulting from numerous theories or models. These maps create self-awareness and are broadly accepted as a helping tool to support learners in their day-to-day learning activities. For the development of conceptual maps needs reflective thinking, cognitive imagination, and good understanding of the subject concept. The article tried to review; the introduction of concept mapping; brief history; essential components; different patterns of use; utilization in nursing education and practice, health sectors, etc.
\end{abstract}

Keywords: Concept Mapping, Nursing Education, Nursing Practice, Patient Care

\section{Introduction}

Concept maps are a schematic representation of subject matter in the model of graphic presents connected with links. It is an educational strategy. Essentially, learns to recognize the graphical presentations and join key concepts by arranging relevant information. Conceptual maps may be effectively utilized to teach cognitive thinking, it helps to rise student abilities in significant thinking in the present era [1]. Concept maps are used to link words, ideas, or elements to a core word or thought with the help of graphics or illustrations. These maps promote or aid the communication of associations and connections in a visual manner. Explicitly, concept maps are used to explain the associations among concepts and their connections in the direction of top-down [2].

\subsection{History of Concept Mapping}

Joseph D. Novak in the year of 1970 was established the concept of "Concept mapping". It helps for the better understanding of the subject information in the form of different shapes, hierarchical graphs, and visual imaginations by using images. It is mainly assisting in the construction of knowledge on any topic. The concept maps are the best example of visual thinking techniques. The best visual thinking techniques in nursing education are concept maps. These maps are frequently used to exemplify ideas and relations among any particular topic and to improve critical thinking capacity among student nurses or among any other group of students in any educational category [3]. Concept maps are widespread usage of graphic design of knowledge has exposed that various advantages can be accomplished by implementing visual mapping systems in various knowledge sharing circumstances [4].

\subsection{Representation of Conceptual Maps}

A conceptual diagram utilizes a graphic conceptual framework to visually organize information or learning 
content with the assist of predefined groups. These groups are generally resulting from numerous theories or models [5]. For the development of conceptual maps needs reflective thinking, cognitive imagination, and good understanding of the subject concept [6]. Few research authors explain that significant learning comes from organizing information as relating concepts or ideas. Particularly, concept mappings promotes careful thought in incorporating evidence and crucial judgments from the clinical area [7].

A concept map will be considered as a format identifying visual knowledge in the sequence of hierarchical graphic system association of connections and links. Essentially, it is very much importance for the development of critical thinking and judgment skills among nursing students by nursing educators in the teaching and clinical settings. Concept mapping is an educational strategy that needs learners to recognize graphical presentation and connect key concepts by arranging and exploring information. These maps can be effectively utilized to educate conceptual thinking, consequently developing the student's ability in reflective thinking in the current younger generation [1].

These maps have been used efficiently in the areas of clinical or practical as well as in educational institutions and may assist the student to focus on the current study topic with excellent visual manner [7]. This type of mapping uses in nursing education regularly to facilitate critical thinking skills among nursing students, which helps students automatically to identify and bridge the gap between nursing theory and practice [8,9]. Moreover, professionally, the competency to adapt the critical thinking practice is easier by concept mapping and may take part of a crucial role in the development of cognitive skills among the students in the necessary areas [10].

Currently, a variety of computerized, feasible options become accessible through the internet. Software might be used by persons to have collaboration with in a group by using concept mapping. These maps may save in digital form and may use to review and to discuss these concepts among people. Different software applications may use as computers, tablets, smart phones to generate visual graphic illustrations of the topic being discussed. These kinds of digital technology tools create wide learning experiences and provide increasing collaboration among all students. Several digital programs are found through the internet for creating concept mapping tools; some tools may available as free access for supporting different study fields. These maps are flexible and allow for mind mapping or concept mapping. These digital concept maps support different file types such as audio or video files, images etc. [11].

\subsection{Essential Components of Conceptual Mapping}

Concepts are interrelated with thinking and learning, preferably, connecting labels should be small and smart, concepts are directed by arrow heads, connected ideas may be short or long, different concept ideas connected by various file formats, possible, simple language transformation, probably, concepts represented by hierarchically manner, each idea represented only once [12].

\subsection{Different Patterns of Conceptual Mapping Are in Use}

Spider - Ideal to utilization of the center theme concepts, Hierarchy - Direction of higher to lower order form of information, Flow chart- Sequential information in linear format, systems - Assist in methods of input and output sequences, Picture - Illustration with picture models, Multidimensional- Use of simple to complex information elaboration, Mandala- Arranging information based on interlocking manner [13].

\section{Implications of Concept Maps in Nursing Education}

Generally, concept maps are identified as innovative educational tactics widely increasing usage in nursing education. These maps are observed as logical measures of learning sequences with simplification, well arranged, and high prioritization may consider. Adding up this, an extensive number of articles in nursing related literature support the usage of concept mapping in nursing education to advance the critical thinking nature among people $[7,11]$.

Concept maps are simple designs, which are used to facilitate or describe and generate knowledge, and furnish a constructive framework for critical analysis and problemsolving techniques. The advantages of concept mapping for patient's welfare and comfort, employee's gratification, and group learning are exhibited. Conceptual maps are observed as new and efficient teaching and learning tools for the student learning process. Concept maps are educational useful tools for teachers and learners; it creates significant knowledge of a specific subject and represents it in a schematic manner [14].

The Conceptual maps assist the students in teaching and learning activities and improve critical thinking potentiality and bring an enthusiastic learning mechanism. Conceptual maps are needful tools to increase cognitive thinking among nursing students in nursing education for the application of theoretical areas into the clinical implements [15]. Concept maps have explored their extensive positive effects on student learning for various study topics and numerous teaching conditions [4]. The basic of visual methods for learning and knowledge exploring is an expansive one, and the different learning requirements and various styles of students may create it essential to utilize concept maps as one type of learning supporting tool among others [2].

These maps are helping for teaching or instructional practice and have a higher impact on for the students' educational success or accomplishments. Effective utilization of modern instructional techniques is very much targeted challenging in nursing education and nursing practice. Concept mapping needs advance practice on various subject topics between different knowledge categories of the nursing learners [16]. Conceptual maps may help the professional development of nurses are also explained by the some 
nursing literatures [17-19].

These maps create self-awareness and are broadly accepted as a helping tool to support learners in their day to day learning activities [20]. Majorly, concept maps are extensively used at the undergraduate level to assist systematizing information and assessing patient data for providing necessary care to the assigned clinical patients [21] Advancing technology with conceptual mapping is a modern teaching and practical technique in the present nursing educations [22]. Some minimal literature can explain the utilization of concept mapping in graduate program levels, these information evidence that concept maps are useful for students in preparing and organizing information connected to research activities and for increasing understanding of difficult concepts [21, 23].

Evidence suggests that critical thinking skills are needed for better clinical practice and for excellent outcome of patient care. Every nursing professional might think about teaching and learning strategies which will promote the development of critical thinking skills among students [15]. Every nursing instructor should educate nursing students how to bridge the clinical and theoretical knowledge with the objective of improving the outcome of patient progress. One of the research studies explains that the weekly concept map extensively increased student commitment and fostered theoretical thinking. Surprisingly, this activity also benefited students through engagement with group work and its ability to improve theory practice knowledge which aid in patient direct care [24].

This is an easy technique for teaching instructors to assess their students' progress by well-structured conceptual mapping of assigning subject matter or topics for simplification and assist in cognitive developmental skills. Concept mapping would have greater identification with regular practices, it is evidenced that it's very much progress towards toward building team or group work engagements, improving brain storm learning activities, keeping sense of knowledge practice among faculty and students. Absolutely, the day-to-day student practices are very crucial among all categories of students for the efficient meeting of their educational and practical developments in their carrier. As per the records of many research studies, for the implementation of concept mapping as constant educational or instructional practice among nursing or various discipline student divisions, it may help concern for the all professional growth [16].

Conceptual mapping helps in clinical teaching and learning activities and improves cognitive skills for the development of the nursing process. It can assist in by facilitation of fulfilling biological and physiological and intellectual needs of the patient and helps in planning nursing care and explain the relationship among concepts. These maps highly support the evidence-based nursing educational practices [7]. The concept mapping can be assisted in focusing on patient health problems and way to assessment of solving problems, identification of health risk and management, nursing care planning and evaluation and guide in expected outcome of patient progress. Concept maps may be used in beneficiary to enhance progressive patient outcome and develop clinical guidance as well as building team efforts among nursing staff, it may beneficiary to patient wellness and brings safety and care takers work happiness and group learning are advanced [14].

Nursing faculty or instructors have a significant role in teaching nursing students regarding the connection of theoretical knowledge to the practicum areas to bring efficient patient recovery with the help of conceptual mappings; it also motivates the students for better group coordination and improves theory as well as practical skills [24]. A researcher identified; conceptual mapping is a clinical teaching-learning activity which may contemplate cognitive thinking by recognition of nonlinear associations between the elements of the nursing process. The research findings of the study were evidence that the utilization of concept maps is an efficient teaching-learning activity and assisted concept mapping is an empirical nursing education approach [7].

Currently, conceptual mapping applications are effective usage under teaching methods in the nursing profession and other educational or instructional disciplines to assess the theoretical and practical knowledge of the students in all educational institutions. The nursing students utilize a special software program to assess patient health problems and explain relations with the problems. This method is very much flexible and helps students to analyze the gaps in the provided information, essentially understanding the crucial problems of the patient, and finding solutions to it. It exercises cognitive thinking ideas, implements in nursing theory and practice, and advances with the competency of technology and speedups the essential interaction among faculties as well as students [25]. It helps in for the creation of new educational strategies in nursing education. It is significantly helping the nursing students to understand the critical questions and assist in finding answers to solve the problems by creation and remembrance of graphical representations. It helps the nursing students and faculty for easy remembrance of subject matters in the form of key points and assists in the preparation of a nursing care plan or preparation of nursing process [26].

There is a great need of critical thinking or cognitive skills needed by nursing professionals. Fundamentally, nursing educators or instructors are trying best for increasing the critical thinking skills among nursing students in all theory and practical aspects. Thus, conceptual maps are identified, as one of the powerful cognitive tools which may increase the knowledge of the students [27].

\section{Utilization of Concept Mapping}

\subsection{Utilization of Concept Mapping in the Nursing Education}

Concept mapping may be a commanding instrument in the educational curriculum for student learners. It assists the students for the better enhancement of the learning capacities among the students' performance in all aspects of the 
curriculum. Easy understanding of the topic; development of creative ideas on the topics; increasing group discussion on new thoughts; simplification of the subject materials; mapping to different concepts or ideas [28].

\subsection{Utilization of Concept Mapping in the Nursing Practice}

Concept maps are very essential in the health care delivery system. It can be utilized by any health care personnel during the delivery of patient care. Assessing and planning of patient care, collaboration of patient care with staff, communicating with patient and family members, identifying gaps in direct patient care, assisting in patient recording and report writing, analyzing health problems of the patient [28].

\section{Conclusion}

Conceptual mapping is a great tool for the development of the cognitive thinking of educational instructors and all categories of students. It assists in easy learning of the subject information by the students and promotion of group discussion among the group of people. Concept maps are widespread usage of graphic design of knowledge has exposed that various advantages can be accomplished by implementing visual mapping systems in various knowledge sharing circumstances. Concept maps have explored their extensive positive effects on student learning for various study topics and numerous teaching conditions. The basic of visual methods for learning and knowledge exploring is an expansive one, and the different learning requirements and various styles of students may create it essential to utilize concept maps as one type of learning supporting tool among others.

\section{Ethics Approval and Consent to Participate}

Not applicable.

\section{Consent for Publication}

Not applicable.

\section{Availability of Data and Materials}

Not applicable.

\section{Authors' Contribution}

Both authors have contributed to the conception of the study, drafting or revising the article, manuscript preparation, gave final approval of the version to be published, and agreed to be accountable for all aspects of the work.

\section{Competing Interests}

The authors declare that they have no competing interests.

\section{References}

[1] Hsu L, Hsieh S-I. Concept maps as an assessment tool in a nursing course. J Prof Nurs Off J Am Assoc Coll Nurs. 2005; 21: 141-9. doi: 10.1016/j.profnurs.2005.04.006.

[2] Eppler MJ. A Comparison between Concept Maps, Mind Maps, Conceptual Diagrams, and Visual Metaphors as Complementary Tools for Knowledge Construction and Sharing. Inf Vis. 2006; 5: 202-10. doi: 10.1057/palgrave.ivs.9500131.

[3] Carter-Templeton H, Sackett Fitzgerald K, Carter M. Application of Concept Mapping as a Visual Thinking Strategy in an Asynchronous Online Graduate Informatics Course. Comput Inform Nurs CIN. 2016; 34: 331-5. doi: 10.1097/CIN.0000000000000279.

[4] Novak JD. Learning, Creating, and Using Knowledge: Concept Maps as Facilitative Tools in Schools and Corporations. 2 2nd 2010 https://www.routledge.com/Learning-Creating-and-UsingKnowledge-Concept-Maps-as-FacilitativeTools/Novak/p/book/9780415991858. Accessed 10 May 2021.

[5] Huff AS. Mapping strategic thought. Chichester; New York: Wiley; 1990.

[6] Schuster PM. Concept Mapping: Reducing Clinical Care Plan Paperwork and Increasing Learning. Nurse Educ. 2000; 25: 76-81.

https://journals.lww.com/nurseeducatoronline/Abstract/2000/0 3000/Concept_Mapping_Reducing_Clinical_Care_Plan.9.a spx. Accessed 10 May 2021 .

[7] Abel WM, Freeze M. Evaluation of concept mapping in an associate degree nursing program. J Nurs Educ. 2006; 45: 356-64. doi: 10.3928/01484834-20060901-05.

[8] Harrison S, Gibbons C. Nursing Student Perceptions of Concept Maps: From Theory to Practice. Nurs Educ Perspect. 2013; 34: 395-9. doi: 10.5480/10-465.

[9] Schmehl P. Introduction to concept mapping in nursing: critical thinking in action. Burlington, MA: Jones \& Bartlett Learning; 2014.

[10] Kinchin I m., Cabot L b., Hay D b. Visualising expertise: towards an authentic pedagogy for higher education. Teach High Educ. 2008; 13: 315-26. doi: $10.1080 / 13562510802045345$.

[11] Shellenbarger T, Robb M. Technology-based strategies for promoting clinical reasoning skills in nursing education. Nurse Educ. 2015; 40: 79-82. doi: 10.1097/NNE.0000000000000111.

[12] Ahlberg M. Varieties of concept mapping.: 5 . https://www.researchgate.net/publication/268177995_Varietie s_of_concept_mapping.

[13] Max C. Kinds of concept maps.: 2. http: //www.ucolick.org/ max/289/Concept\%20Maps/About\%20co ncept $\% 20$ maps/KindsOfConceptMaps.pdf.

[14] Aberdeen S. Concept mapping: a tool for improving patient care. Nurs Stand R Coll Nurs G B 1987. 2015; 29: 49-58. doi: 10.7748/ns.29.48.49.e9903. 
[15] Garwood JK, Ahmed AH, McComb SA. The Effect of Concept Maps on Undergraduate Nursing Students' Critical Thinking. Nurs Educ Perspect. 2018; 39: 208-14. doi: 10.1097/01.NEP.0000000000000307.

[16] Jaafarpour M, Aazami S, Mozafari M. Does concept mapping enhance learning outcome of nursing students? Nurse Educ Today. 2016; 36: 129-32. doi: 10.1016/j.nedt.2015.08.029.

[17] Noonan P. Using concept maps in perioperative education. AORN J. 2011; 94: 469-78. doi: 10.1016/j.aorn.2011.02.013.

[18] Veo P. Concept mapping for applying theory to nursing practice. J Nurses Staff Dev JNSD Off J Natl Nurs Staff Dev Organ. 2010; 26: 17-22. doi: 10.1097/NND.0b013e3181cc2d6f.

[19] Wahl SE, Thompson AM. Concept mapping in a critical care orientation program: a pilot study to develop critical thinking and decision-making skills in novice nurses. J Contin Educ Nurs. 2013; 44: 455-60. doi: 10.3928/00220124-20130916-79.

[20] Daley BJ, Beman SB, Morgan S, Kennedy L, Sheriff M. Concept Maps: A Tool to Prepare for High Fidelity Simulation in Nursing. J Scholarsh Teach Learn. 2017; 17: 17-30. doi: 10.14434/josotl.v17i4.21668.

[21] Taylor LA, Littleton-Kearney M. Concept mapping: a distinctive educational approach to foster critical thinking. Nurse Educ. 2011; 36: 84-8. doi: 10.1097/NNE.0b013e31820b5308.
[22] Harpaz Y. Approaches to Teaching Thinking: Toward a Conceptual Mapping of the Field. Teach Coll Rec. 2007; 109: 1845-74. https://eric.ed.gov/?id=EJ820481. Accessed 10 May 2021.

[23] Bittencourt GKGD, Nóbrega MML da, Medeiros ACT, Furtado LG. Mapas conceituais no ensino de pós-graduação em enfermagem: relato de experiência. Rev Gaúcha Enferm. 2013; 34: 172-172. doi: 10.1590/S1983-14472013000200022.

[24] Hunter Revell SM. Concept maps and nursing theory: a pedagogical approach. Nurse Educ. 2012; 37: 131-5. doi: 10.1097/NNE.0b013e31825041ba.

[25] Taylor J, Wros P. Concept mapping: a nursing model for care planning. J Nurs Educ. 2007; 46: 211-6. doi: 10.3928/01484834-20070501-04.

[26] All AC, Havens RL. Cognitive/concept mapping: a teaching strategy for nursing. J Adv Nurs. 1997; 25: 1210-9. doi: 10.1046/j.1365-2648.1997.19970251210.x.

[27] Gul RB, Boman JA. Concept mapping: A strategy for teaching and evaluation in nursing education. Nurse Educ Pract. 2006; 6: 199-206. doi: 10.1016/j.nepr.2006.01.001.

[28] What is a Concept Map. Lucidchart. https://www.lucidchart.com/pages/concept-map. Accessed 10 May 2021. 